\title{
Kepercayaan Sebagai Anteseden Berbagi Pengetahuan
}

\author{
Endyastuti Pravitasari ${ }^{1 *}$ dan Sri Raharso ${ }^{2}$ \\ ${ }^{1}$ Jurusan Administrasi Niaga, Politeknik Negeri Bandung, Indonesia \\ ${ }^{2}$ Jurusan Administrasi Niaga, Politeknik Negeri Bandung, Indonesia
}

\begin{abstract}
:
This study aims to analyze the effect of trust on knowledge sharing among employees in Telkom Corporate University Center Bandung. A phenomenon employees will be selective for the exchange of knowledge with colleagues. Trust measured by affect based trust and cognition based trust. While, knowledge sharing behavior measured by knowledge donation and collecting. The approach uses the quantitative in total 131 respondents. The results of the analysis highlighted that value of trust in Telkom CorpU Center is in high category with cognitive based trust as the highest dimension of mean. The value of knowledge sharing is in high category with knowledge gathering as the highest dimension of mean.The result also shows significance relationship between trust and knowledge sharing. In order to increase knowledge sharing, trust should improved. Author suggest that leader should telling the truth no matter what, management must build an opportunity to show that teamwork is important as well.
\end{abstract}

Keywords: knowledge sharing, learning, trust

\begin{abstract}
Abstrak:
Penelitian ini bertujuan untuk menganalisis pengaruh kepercayaan terhadap perilaku berbagi pengetahuan antar karyawan di Telkom Corporate University Center Bandung. Fenomena karyawan terbatas pada perilaku saling bertukar pengetahuan dengan rekan kerja. Kepercayaan diukur berdasarkan kepercayaan berbasis kepercayaan dan kepercayaan berbasis kognisi. Sedangkan, perilaku berbagi pengetahuan diukur dengan bantuan pengetahuan dan pengumpulan. Penelitian ini menggunakan pendekatan kuantitatif dengan total 131 responden. Hasil analisis menyoroti bahwa nilai kepercayaan pada Telkom CorpU Center berada pada kategori tinggi dengan kepercayaan berbasis kognitif sebagai dimensi rata-rata tertinggi. Nilai knowledge sharing dalam kategori tinggi dengan knowledge gathering sebagai dimensi dengan rata-rata tertinggi. Hasil penelitian ini juga menunjukkan hubungan yang signifikan antara saling percaya dan perilaku berbagi pengetahuan. Untuk meningkatkan perilaku berbagi pengetahuan, kepercayaan harus ditingkatkan. Penulis menyarankan bahwa pemimpin harus mengatakan yang sebenarnya, tidak peduli apa konsekuensinya, manajemen harus membangun kesempatan untuk menunjukkan bahwa kerja sama tim juga penting.
\end{abstract}

Kata Kunci: berbagi pengetahuan, pembelajaran, kepercayaan

\section{PENDAHULUAN}

PT Telekomunikasi Indonesia Tbk adalah salah satu perusahaan di Indonesia

\footnotetext{
* Email Korespondensi:

Endyastuti Pravitasari

endysps@gmail.com
}

yang berhasil menerapkan Satu Knowledge Management dalam mengembangkan kompetensi agar karyawan bertukar pandangan dan konsep serta berbagi informasi. Knowledge sharing (KS) merupakan inti untuk mencapai 
keberhasilan dan kesuksesan yang paling utama dalam pengimplementasian $K M$. Tanpa berbagi pengetahuan, proses learning dan knowledge creation menjadi terhambat, skala utilitas knowledge tidak mengalami perkembangan dan hanya dimanfaatkan oleh karyawan dengan unit yang terbatas (Tobing, 2012). Secara offline pelaksanaan knowledge sharing difasilitasi oleh community of practice (COP) yang meliputi kegiatan book sharing (bedah buku, resensi), lesson learned, karyawan diberikan kesempatan untuk menyampaikan pengalaman keberhasilan ataupun kegagalannya dalam melaksanakan tugas pekerjaan. Untuk mendukung knowledge management, Telkom membentuk unit bisnis bernama Telkom Corporate University Center (Telkom CorpU Center) dibawah Director Human Capital Management.

$K S$ di Telkom CorpU Center dilaksanakan melalui dua cara, yaitu secara online dan offline. Pelaksanaan secara online, melalui media Kampiun, majalah Patriot 135, dan portal. Data frekuensi upload dan akses dokumen yang dilakukan oleh karyawan Telkom CorpU Center di Kampiun menunjukkan bahwa frekuensi upload dan akses data Kampiun oleh karyawan Telkom CorpU Center di tahun 2015 dan 2016 banyak terjadi pada bulanbulan pelaksanaan kompetisi yaitu bulan Mei, Juni, dan Juli. Diluar dari jadwal kompetisi, penggunaan Kampiun masih sangat jarang dilakukan oleh karyawan Telkom CopU Center.

Menurut hasil wawancara yang dilakukan kepada lima karyawan Telkom CorpU Center, tiga dari lima responden sangat selektif untuk berbagi informasi terkait dengan pekerjaan. Ketika karyawan tidak mempercayai rekan kerja, proses pertukaran informasi akan menjadi minimal. Tiga dari lima responden merasa takut rekan kerja akan mengambil keuntungan dari situasi berbagi pengetahuan. Empat dari lima responden enggan untuk memberi tanggapan terhadap rekan kerja yang sedang melakukan sharing. Banyak pula karyawan yang sulit dipercaya, sebelum melihat tingkah laku rekan kerja tidak sesuai dengan perkataan yang dia utarakan.

Sharing lebih cenderung dilakukan untuk membahas masalah di luar pekerjaan. Selain itu, sistem knowledge management yang diciptakan oleh Telkom dalam bentuk portal (https://kampiun.telkom.co.id) belum diterapkan secara maksimal. Pegawai turut berperan akan penyebaran pengetahuan melalui aplikasi Kampiun. Hal ini karena adanya peraturan di Telkom untuk memenuhi nilai kompetensi yaitu kegiatan upload dokumen. Namun, beberapa pegawai hanya melakukan upload paling banyak satu kali dalam setahun. Upload hanya dilakukan berdasarkan jadi kewajiban memenuhi peraturan saja.

Selain itu, hasil kuesioner pra penelitian kepada 30 responden menyatakan $57 \%$ responden mengetahui track record sebagian besar rekan kerja di academy yang ditempati. Jika dilihat dari fakta lapangan, satu academy di Telkom CorpU Center ditempati oleh rata-rata dua puluh orang karyawan yang terdiri dari senior manager, manager, dan officer. Namun, 43\% responden berpendapat tidak mengetahui track record mereka. Pernyataan kedua mengenai keandalan rekan kerja, $47 \%$ berpendapat bahwa sebagian rekan kerja tidak dapat diandalkan. Pernyataan ketiga mengenai kebebasan berpendapat, $40 \%$ responden takut mengungkapkan pendapat kepada rekan kerja dengan jabatan yang lebih tinggi. Pernyataan keempat masih mengenai kebebasan berpendapat, $67 \%$ responden tidak dapat berbicara secara bebas mengenai ide, perasaan, harapan kepada sebagian besar rekan kerja. Pernyataan kelima mengenai kepercayaan, $63 \%$ berpendapat bahwa tidak seluruh 
rekan kerja dapat dipercaya. Berdasarkan pemaparan diatas, dapat diindikasikan bahwa terjadi penimbunan pengetahuan (knowledge hoarding) oleh individu dan perasaan tidak yakin terhadap rekan kerja.

Tujuan utama dari artikel ini adalah mengidentifikasi tingkat kepercayaan antar karyawan, tingkat perilaku berbagi pengetahuan, serta peran pengaruh kepercayaan terhadap perilaku berbagi pengetahuan di Telkom Corporate University Center Bandung. Artikel ini diharapkan dapat membuka wawasan mengenai topik kepercayaan dan berbagi pengetahuan di organisasi dengan tingkat awareness akan pengetahuan yang tinggi.

\section{KAJIAN LITERATUR Berbagi Pengetahuan}

Menurut Hooff dan Ridder (2004), knowledge sharing adalah proses dimana individu dengan rkan kerja saling mempertukarkan pengetahuan yang mereka miliki. Menurut Khesal, et al (2013:495) "Knowledge sharing is degree to be able to share the knowledge which related to a person's skill to communicate her or his social behavior". Sementara menurut Lumbantobing (2011), knowledge sharing merupakan proses sistematis untuk mengirimkan, mendistribusikan, dan mendiseminasikan pengetahuan dengan konteks multidimensi dari seseorang atau organisasi kepada orang atau organisasi lain yang membutuhkan metode dan media yang variatif. Berbagi pengetahuan merupakan aktivitas yang terkait dalam penyediaan akses informasi bagi karyawan dengan menggunakan jaringan ilmu pengetahuan dalam organisasi (Mulyana \& Wasitowati, 2015). Dari ketiga definisi diatas dapat disimpulkan bahwa knowledge sharing adalah proses sistematis dalam mengirimkan, menyebarkan, serta mendiseminasikan pengetahuan dan konteks multidimensi dari individu atau organisasi, saling bertukar pengetahuan yang berhubungan dengan kemampuan komunikasi dan sosial melalui metoda atau media yang variatif.

Menurut Hogel et al. (2003), berbagi pengetahuan terdiri dari satu set pemahaman bersama terkait dengan penyediaan akses karyawan untuk informasi yang relevan dan membangun dan menggunakan jaringan pengetahuan dalam organisasi. Reid (2003) mengungkapkan bahwa berbagi pengetahuan membentuk kesempatan untuk memaksimalkan kemampuan organisasi dalam mendapati kebutuhan dengan menghasilkan solusi yang efisien dengan pencapaian keuntungan kompetitif perusahaan.

Berbagi pengetahuan berkaitan dengan kemampuan karyawan untuk melakukan sosialisasi. Cara yang paling sukses untuk mengukur kegiatan berbagi pengetahuan adalah dengan melacak aliran pengetahuan di antara karyawan. Organisasi tidak dapat membuat pengetahuan sendiri tanpa adanya inisiasi dari individu dan interaksi yang dilakukan oleh kelompok. Menurut Nonaka \& Takeuchi (1995), knowledge can be strengthened at the group level through dialogue, discussion, experience sharing, and observation. Dapat diartikan bahwa pengetahuan dapat diperkuat dengan menggunakan kelompok melalui dialog, diskusi, berbagi pengalaman, dan observasi. Menurut Hoof dan Ridder (2004) knowledge sharing terdiri dari dua proses yaitu knowledge donating dan knowledge collecting. Menurut Kasemsap (dalam Raharso dan Tjahjawati, 2016:103) "knowledge donating merupakan komunikasi yang terjadi ketika seorang individu diharapkan mentransfer intellectual capital mereka". Menurut Hoof dan Ridder (2004), knowledge donating merupakan komunikasi yang terjadi ketika seorang individu diharapkan mentransfer modal intelektual mereka. Dari kedua 
pengertian diatas, dapat disimpulkan bahwa knowledge donating merupakan komunikasi dari seorang individu yang diharapkan membagi modal intelektual mereka kepada orang lain. Selanjutnya, knowledge collecting menurut Raharso dan Tjahjawati (2016) merupakan usaha mempersuasi orang lain agar mereka mau membagi apa yang mereka ketahui. Sedangkan menurut Hoof dan Ridder (2004), knowledge collecting merupakan usaha mempersuasi orang lain untuk membagi apa yang mereka ketahui. Dapat disimpulkan bahwa knowledge collecting merupakan usaha persuasif untuk membagi pengetahuan yang mereka miliki.

\section{Kepercayaan}

Balogun \& Adetula, (2015:37) menyebabkan bahwa kepercayaan adalah suatu situasi psikologis yang terdiri dari niat untuk menerima kelemahan dilandaskan pada harapan positif dari niat atau perilaku lain. Lumbantobing (2011) mengemukakan bahwa interpersonal trust merupakan kesediaan seseorang untuk membukakan vulnerability atau kelemahannya kepada orang lain yang perilakunya tidak dapat dikendalikan. Sementara menurut Mayer (dalam Heyns \& Rothmann, 2015:2). Dapat diartikan bahwa kepercayaan adalah kesediaan satu pihak untuk menjadi rentan terhadap tindakan pihak lain berdasarkan pada harapan bahwa pihak lain akan melakukan tindakan tertentu yang penting untuk trustor, dengan mengabaikan kemampuan untuk memantau atau mengontrol pihak lain.

Menurut Ng \& Chua (dalam Zhang, 2014:22). Kepercayaan adalah keyakinan terhadap niat baik orang lain dan harapan bahwa orang lain akan bertindak dengan cara yang menguntungkan. Berdasarkann keempat pengertian diatas dapat ditarik kesimpulan bahwa kepercayaan merupakan suatu keadaan psikologis yang terdiri dari niat untuk menerima kelemahan dan membukakan kelemahan kepada orang lain berdasarkan harapan positif dari niat atau perilaku serta ekspektasi.

Elemen paling penting untuk mempengaruhi pembelajaran dalam organisasi adalah kepercayaan. McAllister (1995:25) menyatakan bahwa kepercayaan interpersonal merupakan fenomena yang merasuk di dalam kehidupan organisasi, maka saling percaya antar karyawan perlu menjadi budaya dalam suatu organisasi yang mengimplementasikan manajemen pengetahuan. Dengan tugas utama organisasi adalah mengintegrasikan pengetahuan khusus dari individu yang berbeda (Zuhal, 2010). Menurut Mayer.et al, (1995) ada tiga unsur kepercayaan dalam karakteristik trustee yaitu ability, benevolence, dan integrity. Kemampuan menurut Mayer et al, (1995) adalah keterampilan, kompetensi, dan karakteristik yang memungkinkan satu pihak memiliki pengaruh dalam domain tertentu. Kemampuan spesifik trustee mungkin sangat kompeten di beberapa bidang teknis, memberikan rasa layak dipercaya dengan tugas-tugas yang berkaitan di area tersebut. Benevolence (perbuatan baik/kebajikan) merujuk pada sejauh mana trustee diyakini ingin berbuat baik kepada trustor, selain dari motif keuntungan seperti loyalitas, keterbukaan, kepedulian, dan dukungan.

Integrity menunjuk apakah trustee memiliki nilai-nilai inti untuk berprilaku. Integritas dapat dinilai dengan memeriksa perilaku sebelumnya, reputasi, kesamaan antara perilaku trustee dengan keyakinan pribadi trustor dan konsistensi antara katakata dan tindakan (Heyns \& Rothmann, 2015). Menurut McAllister(1995), bukti empiris dari literatur sosial-psikologis pada kepercayaan dalam hubungan yang mendukung perbedaan antara dua bentuk kepercayaan, yaitu affect-based trust dan cognition-based trust sebagai dua dimensi berbagi pengetahuan pada penelitian ini. 
Affect based trust merupakan kecenderungan untuk percaya akan ketulusan dan niat baik seseorang, sedangkan cognitive based trust yaitu kecenderungan untuk percaya akan kemampuan dan kompetensi rekan kerja (McAllister, 1995). Kepercayaan menghormati orang lain karena alasan dan bukti dari kompetensi, tanggung jawab, dan kehandalan sebagai kriteria untuk menilai kepercayaan.

\section{Hubungan Kepercayaan dan Berbagi Pengetahuan}

Kepercayaan merupakan faktor penting dalam tim dan organisasi untuk menciptakan suasana berbagi pengetahuan (Nonaka \& Takeuchi, 1995). Menurut Heyns \& Rothmann (2015) kepercayaan dipengaruhi oleh kecenderungan (propensity) dan kelayakan untuk dipercaya (trustworthiness). Dengan tidak adanya alasan yang kuat, banyak orang tidak akan berbagi pengetahuan jika mereka tidak memiliki perasaan yang baik dan kepercayaan (Ellis dalam Khesal et al, 2013). Terdapat dampak yang sangat potensial dari kepercayaan terhadap berbagi pengetahuan, (Zhang, 2014). Menurut Khesal et al, (2013) menguji hubungan kepercayaan dengan prilaku berbagi pengetahuan, dengan kesimpulan keperccayaan sangat penting untuk menghadirkan situasi yang transparan dalam berbagi dan memanfaatkan pengetahuan. Hasil penelitian Tobing (2012) menghasilkan kesimpulan bahwa trust memiliki dampak positif terhadap knowledge sharing. Hasil penelitian Elianto \& Wulansari (2016) menunjukkan bahwa interpersonal trust membuat efek positif terhadap knowledge sharing. Begitupun dengan hasil penelitian. Balogun \& Adetula (2015) yang menunjukan bahwa trust berpengaruh pada keingingan untuk berbagi dan menggunakan tacid knowledge.
Berdasarkan kajian tersebut, maka hipotesis yang diambil pada penelitian ini adalah sebagai berikut, Terdapat pengaruh positif yang signifikan antara kepercayaan dengan perilaku berbagi pengetahuan karyawan di Telkom Corporate University Center Bandung.

\begin{tabular}{|c|c|}
$\begin{array}{c}\text { Variabel X } \\
\text { Kepercayaan (Trust) } \\
\text { McAllister (1995) }\end{array}$ & $\longrightarrow \begin{array}{c}\text { Variabel Y } \\
\text { Berbagi Pengetahuan } \\
\text { (Knowledge Sharing) } \\
\text { Hoof \& Ridder (2004) } \\
\text { - Affect based trust } \\
\text { Cognitive based trust }\end{array}$ \\
$\begin{array}{c}\text { Knowledge donating } \\
\text { - Knowledge collecting }\end{array}$ \\
\hline
\end{tabular}

Sumber: Olah Data (2017)

Gambar 1. Model Penelitian

\section{METODE PENELITIAN}

Responden penelitian ini adalah 131 karyawan Telkom Corporate University Center Bandung yang diambil secara proporsional sesuai dengan jumlah unitnya dengan teknik proportionate stratified random sampling yang mengambil sampel dari populasi secara acak dan berstrata secara proporsional (Riduan, 2014).

Tabel 1. Identitas Responden

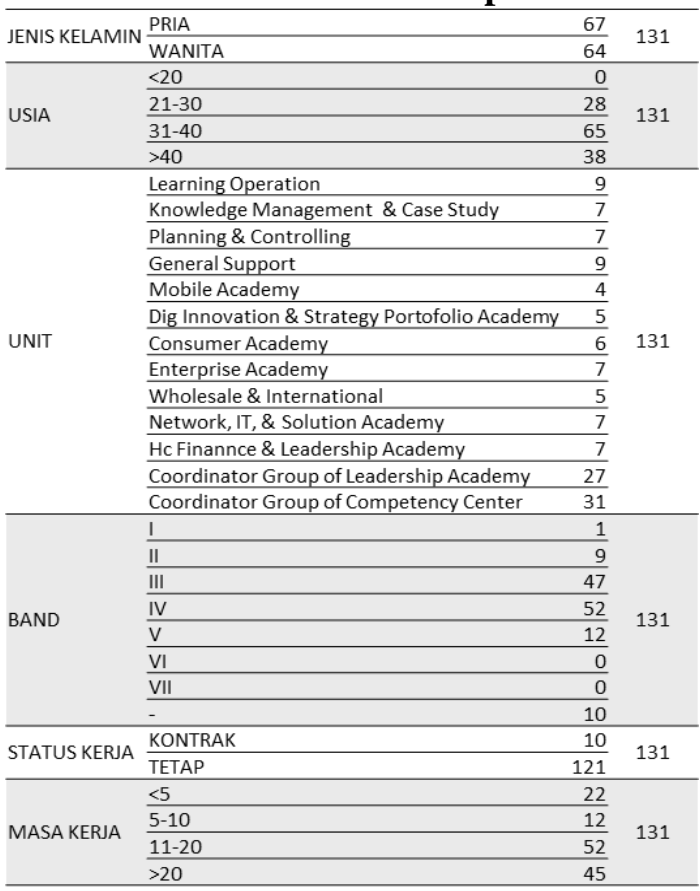

Sumber: Olah Data (2017) 
Kuesioner digunakan sebagai instrumen untuk memperoleh data primer dengan menggunakan skala pengukuran Likert (1-5) untuk menguji apakah responden setuju atau tidak setuju dengan butir pernyataan. Item-item pernyataan yang digunakan dalam penelitian ini diidentifikasi dari kajian pustaka oleh Mayer et al. (1995), dan Hoof dan Ridder (2004) telah melalui uji coba validitas dan reliabilitas kepada 131 responden.

Tabel 2. Operasional Variabel

\begin{tabular}{|c|c|c|c|c|}
\hline \multirow[t]{2}{*}{\begin{tabular}{|l|} 
Variabel \\
Trust
\end{tabular}} & $\begin{array}{l}\text { Dimensi } \\
\text { Cognitive } \\
\text { Based Trust }\end{array}$ & $\begin{array}{l}\text { Indikator } \\
\text { - Able } \\
\text { - Believed }\end{array}$ & $\begin{array}{l}\text { Skala } \\
\text { Likert }\end{array}$ & $\begin{array}{l}\text { Item No. } \\
1,2,6 \\
3,4,5\end{array}$ \\
\hline & $\begin{array}{l}\text { Affective Based } \\
\text { Trust }\end{array}$ & $\begin{array}{l}\text { - Connected } \\
\text { - Dependeble }\end{array}$ & Likert & \\
\hline \multirow[t]{2}{*}{$\begin{array}{l}\text { Knowledge } \\
\text { Sharing }\end{array}$} & $\begin{array}{l}\text { Knowledge } \\
\text { Donating } \\
\text { Kemampuan } \\
\text { karyawan untuk } \\
\text { menyampaikan } \\
\text { pengetahuan } \\
\text { yang dimiliki, } \\
\text { meliputi } \\
\text { pengalaman } \\
\text { kerja, gagasan, } \\
\text { keahlian dan } \\
\text { informasi } \\
\text { kontekstual } \\
\text { kepada } \\
\text { karyawan yang } \\
\text { lain } \\
\end{array}$ & $\begin{array}{l}\text { - Berbagi } \\
\text { keterampilan } \\
\text { kerja baru } \\
\text { - Berbagi } \\
\text { informasi baru } \\
\text { - Berbagi } \\
\text { pengetahuan di } \\
\text { perusahaan }\end{array}$ & Likert & $\begin{array}{l}1-2 \\
3-4 \\
5\end{array}$ \\
\hline & $\begin{array}{l}\text { Knowledge } \\
\text { Collecting } \\
\\
\text { Kemampuan } \\
\text { karyawan untuk } \\
\text { mengumpulkan } \\
\text { pengetahuan } \\
\text { dari karyawan, } \\
\text { meliputi } \\
\text { pengetahuan } \\
\text { pengalaman } \\
\text { kerja, gagasan, } \\
\text { keahlian dan } \\
\text { informasi } \\
\text { kontekstual. }\end{array}$ & $\begin{array}{l}\text { - Mengumpulkan } \\
\text { pengetahuan } \\
\text { baru } \\
\text { - Mengumpulkan } \\
\text { informasi baru } \\
\text { tentang } \\
\text { pekerjaan } \\
\text { - Mengumpulkan } \\
\text { ide-ide baru } \\
\text { - Mengumpulkan } \\
\text { ilmu baru } \\
\text { tentang } \\
\text { pekerjaan dari } \\
\text { kompetensi } \\
\text { orang lain. }\end{array}$ & Likert & $6-10$ \\
\hline
\end{tabular}

Sumber: Olah Data (2017)

\section{HASIL DAN PEMBAHASAN}

Instrumen penelitian dikatakan valid jika alat ukur yang digunakan dalam penelitian dapat mengukur apa yang seharusnya diukur atau sahih. Menurut Noor (2014) uji validitas dilakukan pada setiap item soal atau nilai $r_{\text {hitung }}$ yang bisa dilihat pada kolom Corrected Item-Total Correlation. Nilai $\mathrm{r}_{\text {hitung dibandingkan }}$ dengan nilai $r_{\text {tabel }}$ dimana degree of freedom (df) $=\mathrm{n}-2$ didapatkan hasil $\mathrm{df}=129$. Karena penelitian ini menggunakan tingkat kesalahan 5\% didapat nilai $\mathrm{r}_{\text {tabel }}$ 0,1716.

Penulis melakukan dua kali uji dengan teori yang berbeda, yang pertama menggunakan Person Product Moment (Riduan, 2014) dan melihat dari nilai pada tabel Cronbach's alpha if item deleted. Berdasarkan hasil pengujian validitas variabel kepercayaan diketahui bahwa koefisien korelasi $\left(\mathrm{r}_{\text {tabel }}\right) 11$ item pernyataan variabel $\mathrm{X}$ lebih besar dari 0,1716. Koefisien korelasi ( $\mathrm{r}_{\text {tabel}}$ ) pada 11 item pernyataan variabel berbagi pengetahuan lebih besar dari 0,1716. Dapat disimpulkan bahwa seluruh item variabel kepercayaan dan berbagi pengetahuan dinyatakan valid.

Standard nilai reliabilitas suatu alat ukur adalah > 0,6 (Sekaran dalam Priyatno, 2013). Hasil uji reliabilitas untuk variabel kepercayaan pada kolom Cronbach's alpha menunjukkan angka 0,760. Sedangkan variabel berbagi pengetahuan pada kolom Cronbach's alpha menunjukkan angka 0,854. Dapat diartikan bahwa reliabilitas kedua variabel tergolong baik.

\section{Tingkat Kepercayaan}

Ketika seseorang percaya kepada rekan kerjanya, maka orang tersebut bisa sangat mudah dikritisi, diserang, bahkan disudutkan. Menurut Davenport \& Prusak (dalam Raharso \& Tjahjawati, 2016) elemen paling penting untuk mempengaruhi pembelajaran dalam organisasi adalah kepercayaan. Kepercayaan merupakan fenomena yang merasuk di dalam kehidupan organisasi, maka saling percaya antar karyawan perlu menjadi budaya dalam suatu organisasi yang mengimplementasikan manajemen pengetahuan (McAllister, 1995). Menurut hasil analisis deskriptif diperoleh bahwa kepercayaan di Telkom Corporate University Center berada pada kategori tinggi dengan mean 3,81. Dari kedua 
dimensi pada variabel kepercayaan, dimensi dengan nilai mean tertinggi adalah kepercayaan kognitif yaitu sebesar 3,82. Sedangkan kepercayaan afektif merupakan dimensi dengan nilai mean terendah dengan nilai 3,79. Peningkatan pada variabel kepercayaan terutama pada indikator terhubung yang merupakan indikator dengan mean terendah yaitu sebesar 3,78.

\section{Tingkat Berbagi Pengetahuan}

$\begin{array}{lcrr} & \text { Variabel berbagi pengetahuan } \\ \text { terdiri dari dua dimensi yaitu } & \text { duan } \\ \text { menyumbangkan } & \text { pengetahuan dan }\end{array}$
mengumpulkan pengetahuan. Menurut Hoof dan Ridder (2004), menyumbangkan pengetahuan merupakan komunikasi yang terjadi ketika seorang individu diharapkan mentransfer modal intelektual mereka. Selanjutnya mengumpulkan pengetahuan menurut Raharso dan Tjahjawati (2016) merupakan usaha mempersuasi orang lain agar mereka mau membagi apa yang mereka ketahui.

Dapat dilihat nilai rata-rata dari variabel berbagi pengetahuan sebesar 3,94 yang artinya. Hal ini mengindikasikan bahwa berbagi pengetahuan di Telkom CorpU Center berada dalam kategori tinggi. Dari kedua dimensi pada variabel berbagi pengetahuan (Y), dimensi dengan nilai mean terendah adalah menyumbangkan pengetahuan yaitu sebesar 3,90. Sedangkan mengumpulkan pengetahuan merupakan dimensi dengan nilai mean tertinggi dengan nilai 4,01. Dapat dipahami bahwa karyawan Telkom CorpU Center cenderung mengumpulkan pengetahuan dibanding dengan menyumbangkan pengetahuan. Hal ini sejalan dengan indikasi adanya knowledge hoarding.

\section{Hubungan Kepercayaan Terhadap Berbagi Pengetahuan}

Nilai korelasi antara variabel kepercayaan dengan berbagi pengetahuan adalah 0,567. Mengacu pada interpretasi koefisien dan korelasi, maka nilai korelasi sebesar 0,577 masuk ke dalam interval 0.40 - 0.599 yang berarti berkorelasi sedang (Riduan, 2014). Jika dilihat dari masingmasing variabel, nilai Pearson Correlation menunjukkan nilai yang positif, berarti semakin tinggi kepercayaan maka semakin meningkat perilaku berbagi pengetahuan.

Tabel 3. Statistik Deskriptif \& Korelasi

\begin{tabular}{lcccrrr}
\hline No Dimensi & Mean SD & 1 & 2 & 3 & 4 \\
\hline 1 Cognitive based trust & 3.82 & 0.55 & 1 & 0.233 & 0.155 & 0.349 \\
2Afective based trust & 3.79 & 0.54 & - & 1 & 0.129 & 0.291 \\
3 Knowledge Collecting & 3.90 & 0.60 & - & - & - & 0.413 \\
4 Knowledge Donating & 4.01 & 0.54 & - & - & - & 1 \\
\hline
\end{tabular}

Sumber: Olah Data PASW (2017)

Menurut Wu et al (dalam Wang \& Noe, 2010) kepercayaan dianggap penting untuk perilaku berbagi pengetahuan karena seseorang memberikan pengetahuannya kepada orang lain dengan mengharapkan timbal balik. Kepercayaan sendiri berada dalam koridor motivasi (Wang \& Noe, 2010). Berdasarkan analisis regresi linear sederhana yang dilakukan pada penelitian ini, diperoleh model regresi $\mathrm{Y}=11,219+$ 0,669X. Nilai dari koefisien determinasi pada penelitian ini sebesar $33,3 \%$ sedangkan sisanya dipengaruhi oleh hal lain. Berikut merupakan gambar jika dilihat dari masing-masing dimensi,

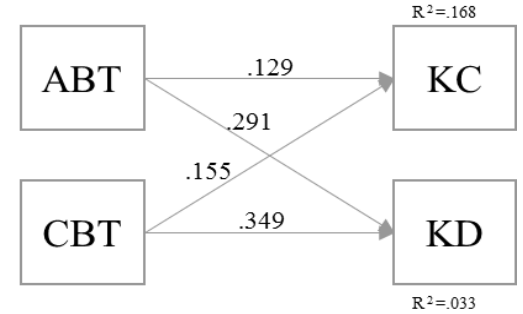

Sumber: Olah Data (2017)

Gambar 2. Pengaruh Antar Dimensi

Hal ini sesuai dengan banyaknya faktor pengaruh berbagi pengetahuan yang telah dijelaskan sebelumnya, dimana kepercayaan merupakan subfaktor dari motivasi. Hasil $\mathrm{F}$ hitung $\left(\mathrm{F}_{\text {hitung }}\right)>\mathrm{F}$ Tabel $\left(F_{\text {tabel }}\right)$ yaitu $61,076>3,914$. Menurut 
Arikunto (2010) Jika $F_{\text {hitung }} \geq F_{\text {tabel }}$ dengan taraf signifikan $5 \%$ maka interpretasinya adalah $\mathrm{H}_{0}$ ditolak dan $\mathrm{H}_{\mathrm{a}}$ diterima. Berdasarkan hasil perhitungan yaitu 8,023 $>1,97852$ dimana $t_{\text {hitung }}>t_{\text {tabel }}$ tingkat signifikansi $t_{\text {hitung }}<0,05$ atau $t_{\text {hitung }}>$ dari $\mathrm{t}_{\text {tabel }}$ maka $\mathrm{H}_{0}$ ditolak dan $\mathrm{H}_{\mathrm{a}}$ diterima. Hal ini menunjukkan bahwa kepercayaan (trust) berpengaruh signifikan terhadap berbagi pengetahuan (knowledge sharing) di Telkom CorpU Center.

Hal tersebut sejalan dengan hasil penelitian Islam et al (2011:5906) "There is a positive relationship between trust among co-workers and knowledge sharing". Berdasarkan hasil analisis regresi, nilai $37,3 \%$ dijelaskan oleh trust, communication, leadership, dan reward. Hasil penelitian Tobing (2012) menghasilkan kesimpulan bahwa trust memiliki dampak positif terhadap knowledge sharing. Hasil penelitian Elianto \& Wulansari (2016) menunjukkan bahwa interpersonal trust membuat efek positif terhadap knowledge sharing. Menurut Wang \& Noe (2010:118) “cultural dimensions that likely influence knowledge sharing have been identified, but trust has attracted the most research attention". Dapat diartikan bahwa dimensi budaya yang sekiranya mempengaruhi berbagi pengetahuan sudah teridentifikasi, tetapi kepercayaan merupakan faktor yang menarik perhatian peneliti.

Oleh karena itu manajemen Telkom CorpU Center harus memperhatikan kepercayaan antar karyawan agar dapat meningkatkan berbagi pengetahuan yang terjadi di perusahaan sehingga tujuan dapat tercapai. Kepercayaan dapat membantu meringankan biaya berbagi pengetahuan (Wang \& Noe 2010).

\section{KESIMPULAN DAN SARAN Kesimpulan}

1. Kepercayaan di Telkom Corporate University Center berada pada kategori tinggi. Dimensi kepercayaan kognitif memiliki nilai mean yang lebih tinggi dibandingkan dengan kepercayaan afektif artinya karyawan kecenderungan untuk percaya akan kemampuan seseorang dibanding dengan ketulusan dan niat baiknya.

2. Perilaku berbagi pengetahuan di Telkom Corporate University Center berada pada kategori tinggi. Dimensi mengumpulkan pengetahuan memiliki nilai mean yang lebih tinggi dibanding dengan dimensi menyumbangkan pengetahuan dapat diartikan bawa karyawan Telkom CorpU Center memiliki kecenderungan untuk mengumpulkan pengetahuan dibanding dengan menyumbangkan pengetahuan.

3. Besarnya pengaruh kepercayaan terhadap perilaku berbagi pengetahuan di Telkom CorpU Center yaitu sebesar $33,3 \%$. Sisanya sebesar $66,7 \%$ dipengaruhi oleh faktor-faktor lain yang tidak dijelaskan dalam penelitian ini seperti personality, kepuasan dalam bekerja, budaya organisasi, reward, teknologi, dan lain sebagainya.

\section{Saran}

Meskipun hasil yang di dapat tinggi, Telkom Corporate University Center yang merupakan unit pembelajaran di Telkom Group sebaiknya selalu melakukan perbaikan yang berhubungan dengan perilaku berbagi pengetahuan maupun kepercayaan karyawan.

Menyumbangkan pengetahuan perlu ditingkatkan dengan cara membangun kesempatan untuk memperlihatkan bahwa kerjasama dalam tim merupakan hal yang penting juga. Telkom CorpU Center bisa melakukan penilaian tim kerja dan mengumumkannya pada Telkom CorpU Award yang biasa dilaksanakan setiap tahun. Pembiasaan umpan balik perlu 
dilaksanakan oleh manajemen pusat untuk membangun budaya keterbukaan dengan andil dari leader kelompok kerja.

Konsistensi manajemen Telkom CorpU Center memberikan perhatian terhadap kepercayaan antarpegawai agar dapat meningkatkan perilaku berbagi pengetahuan yang terjadi di perusahaan. Manajemen membuat peraturan yang mewajibkan pimpinan mendorong berbagi pengetahuan. Forum pimpinan bisa melakukan diskusi klinis dalam rangka berbagi pengetahuan. Setiap keberhasilan di suatu kelompok kerja dapat dibagikan oleh para pimpinan melalui Kampiun.

\section{DAFTAR PUSTAKA}

Arikunto, S. (2010). Prosedur Penelitian Suatu pendekatan praktik. Jakarta: PT Rineka Cipta.

Balogun, A. G., \& Adetula, G. A. (2015). Dimensions of trust as predictors of willingness to share and use tacit knowledge among health workers in Nigeria. International Journal of Research Studies in Management, 4(12), 35-44.

Elianto, W., \& Wulansari, N. A. (2016). Building Knowledge Sharing Intention with Interpersonal Trust as a Mediating Variable. Jurnal Management Teknologi, 15(1), 6776.

Heyns, M., \& Rothmann, S. (2015). Dimensionality of trust: An analysis of the relations between propensity, trustworthiness, and trust. AOSIS Open Journal, 1-12.

Hogel, M. P. (2003). Team-level antecedents of individuals' knowledge networks. Decision Sciences, 34, No 4, 741-770.

Hoof, B. V., \& Ridder, J. A. (2004). Knowledge Sharing in Context: The Influence of Organizational Commitment, Communication Climate Use On Knowledge
Sharing. Journal of Knowledge Management, 117-130.

Islam, M. Z., Ahmed, S. M., Hasan, I., \& Ahmed, S. U. (2011). Organizational culture and knowledge sharing: Empirical evidence from service organizations. African Journal of Business Management, 5(14), 59005909.

Khesal, S. M., Samadi, B., Musram, H. A., \& Zohoori, M. (2013). The Impact of Trust on Knowledge Sharing. Interdisciplinary Journal of Contemporary Research in Business, 495-501.

Lumbantobing, P. (2011). Manajemen Knowledge Sharing Berbasis Komunitas (1st Edition ed.). Bandung: Knowledge Management Society Indonesia.

Mayer, R. C., Davis, J. H., \& Schoorman, F. D. (1995). An Integrative Model of Organizational Trust. In R. C. Mayer, J. H. Davis, \& F. D. Schoorman, The Academy of Management Review, (pp. 709734). Academy of Management.

McAllister, D. J. (1995, February). Affectand Cognition-Based Trust as Foundations for Interpersonal Cooperation in Organizations. Academy of Management Journal, 24-59.

Mulyana, M. A., \& Wasitowati. (2015). Pengaruh Knowledge Donating dan Knowledge Collecting terhadap Innovation Capability Kasus Pengembangan UKM Batik di Provinsi Jawa Tengah-Indonesia. Jurnal Manajemen Teknologi, 14, 246-264.

Nonaka, I., \& Takeuchi, H. (1995). The Knowledge-Creating Company. New York: Oxford University Press, Inc. 
Noor, J. (2014). Metode Penelitian. Jakarta: Kencana.

Priyatno, D. (2013). Mandiri Belajar Analisis Data Dengan SPSS. Yogyakarta: Medikom.

Raharso, S., \& Tjahjawati, S. S. (2016). Organisasi Berbasis Pengetahuan Melalui Knowledge Sharing. Bandung: Alfabeta.

Reid, F. (2003). Creating a knowledge sharing culture among diverse business units, . No. 3, pp. 43-9. Employment Relations Today, 30, No 3, 43-49.

Riduan. (2014). Metode dan Teknik Menyusun Tesis. Bandung: Alfabeta.

Tobing, R. F. (2012). Hubungan Trust dan Knowledge Self Efficacy Terhadap Knowledge Sharing Serta Dampak Knowledge Sharing Terhadap Kinerja. Jakarta: FPSI UI.

Wang, S., \& Noe, R. A. (2010). Knowledge sharing: A review and directions for future research. Human Resource Management Review, 20, 115-131.

Washington, M. G. (2013). Trust and Project Performance: The Effects of Cognitive-Based and AffectiveBased Trust on Client-Project Manager Engagements. Pennsylvania: University of Pennsylvania Scholarly Commons.

Zhang, M. J. (2014). The Impacts of Trust and Feelings on Knowledge Sharing among Chinese Employees. New England Journal of Entrepreneurship, 17, No 1, 1-8.

Zuhal. (2010). Knowledge and Innovation Platform Kekuatan Daya Saing. Jakarta: PT Gramedia Pustaka Utama 